\title{
Modos de habitar y creación fotográfica con jóvenes del Kilómetro 4I
}

\author{
Andrés Uriel Pérez-Vallejo, Mg. \\ Universidad de Caldas, Colombia*
}

Luz Amparo Arroyave-Montoya, Mg.

Universidad de Manizales-Cinde, Colombia**

andres.perez@ucaldas.edu.co

\section{Resumen (analítico)}

En este artículo de investigación cualitativa, la tecnología fotográfica y la memoria visual se convierten en plataformas para producir expresiones artísticas de reconciliación. En tal sentido, la creación fotográfica se usó como medio para exteriorizar significados e interpretaciones visuales sobre un territorio. Estudiantes de una institución educativa rural participaron en talleres de creación fotográfica y laboratorios de fundamentación sobre memoria y reconciliación. Este trabajo empírico permitió aplicar instrumentos de observación participante, explorando el acto creativo a través de una guía de elementos que potenciaron posturas críticas de los jóvenes hacia el territorio. Los resultados de un modelo de acciones creativas, aplicado a procesos de pensamiento crítico, permitieron comprobar que el autorretrato fotográfico se convierte en un artefacto comunicativo autorreferenciado socialmente.

\section{Palabras clave}

Fotografía, tecnología, memoria, diseño, creación artística, joven, territorio ocupado.

\section{Thesauro}

Tesauro de Ciencias Sociales de la Unesco.

\section{Para citar este artículo}

Pérez-Vallejo, A. U., \& Arroyave-Montoya, L. A. (2020). Modos de habitar y creación fotográfica con jóvenes del Kilómetro 41. Revista Latinoamericana de Ciencias Sociales, Niñez y Juventud, 18(3), 1-28. https://dx.doi.org/10.11600/1692715x.18304

Historial

Recibido: 20.09.2019

Aceptado: 10.02 .2020

Publicado: 25.08.2020

\section{Información artículo}

Este artículo se deriva del cruce investigativo de dos investigaciones: Modelo de la acción creadora en diseño fotográfico, realizada desde febrero de 2014 hasta el presente año y Poéticas de reconciliación con el río Cauca: el habitar de los jóvenes en el Kilómetro 41, realizada desde agosto de 2016 hasta al presente año. Las dos investigaciones coinciden en un abordaje de temas relacionados con la cultura y la memoria visual, pero con propósitos diferentes desprendidos de los objetos de estudio. Área: artes y humanidades. Subárea: diseño y ciencias sociales. 


\title{
Modes of living and photographic creation with young people from Kilometer 4I
}

\begin{abstract}
(analytical)
In this qualitative research article, photographic technology and visual memory are used in platforms to produce artistic expressions of reconciliation. Photographic creation was used to express meanings and visual interpretations of a territory. Students from a rural school participated in photographic creation workshops and activities focused on memory and reconciliation. This empirical work facilitated the application of participant observation instruments, exploring the act of creation through a handbook that promoted critical thinking for young people regarding the territory. The results of a creative action model applied to critical thought processes verified that the photographic self-portrait becomes a socially self-referenced communicative artifact.
\end{abstract}

Keywords

Photography, technology, memory, design, artistic creation, young, occupied territory.

\section{Modos de vida e criação fotográfica com jovens do Quilômetro 4I}

\section{Resumo (analítico)}

Neste artigo de pesquisa qualitativa, a tecnologia fotográfica e memória visual tornam-se plataformas para produzir expressões artísticas de reconciliação. Nesse sentido, a criação fotográfica foi utilizada como um meio de externalizar significados visuais e interpretações de um território. Os alunos da instituição educacional rural Giovanni Montini participam de oficinas de criação fotográfica e de laboratórios de fundamentação em memória e reconciliação. Este trabalho empírico permitiu a aplicação de instrumentos de observação participante, explorando o ato criativo por meio de um guia de elementos (estruturação, navegação, programação e representação) que impulsionaram as posições críticas dos jovens em relação ao território. Os resultados de um modelo de ações criativas, aplicadas aos processos de pensamento crítico, permitiram verificar que o auto-retrato fotográfico torna-se um dispositivo comunicativo socialmente auto-referenciado..

\section{Palavras-chave}

Fotografia, tecnología, memoria, design, criação artística, joven, território ocupado.

Información autores

[*] Maestro en Artes Plásticas, Universidad Caldas. Especialista en Docencia Universitaria, Universidad de Caldas. Magíster en Diseño y Creación Interactiva, Universidad de Caldas. Estudiante de Doctorado en Diseño y Creación, Universidad de Caldas. (iD 0000-0001-5239-9111. Correo electrónico:

andres.perez@ucaldas.edu.co

[**] Maestra en Artes Plásticas, Universidad de Caldas. Magíster en Diseño y Creación Interactiva, Universidad de Caldas. Estudiante de Doctorado en Ciencias Sociales, Niñez y Juventud, Universidad de Manizales-Cinde. Correo electrónico: larroyavemon@yahoo.com (iD) 0000-0003-0539-4777. 


\section{Introducción}

E 1 (corregimiento Colombia del municipio de Manizales). Es un microuniverso colombiano donde sus habitantes coexisten con los vestigios de las ruinas de la carrilera que bordea el río Cauca y los despojos de la Hacienda Potrerillo - expropiada a Roberto Escobar (hermano de Pablo Escobar)—. En Potrerillo se asentó, en los últimos años, una invasión que se ha transformado en parte de la comunidad que habita la ribera. Estas características especiales del territorio han afectado la cultura, la convivencia y los modos de habitar de los jóvenes y las jóvenes rurales. Las condiciones sociales de sus familias hacen que se renueven las maneras de interpretar los lugares, resignificando el concepto de habitar a través de la reflexión del territorio.

El presente artículo reporta una investigación sobre creación fotográfica utilizada como medio para exteriorizar significados e interpretaciones visuales de los jóvenes hacia un territorio, donde el habitar, la memoria y la identidad son factores que aportan al desarrollo de posturas críticas. Esta experiencia es relevante porque permitió a jóvenes -con pocos conocimientos sobre creación fotográfica y comunicación visual- ser sujetos activos en un entorno de roles sociales, haciendo uso de diferentes percepciones sobre el territorio como insumo para la creación de autorretratos fotográficos, invitándolos a interiorizar y proyectar sus lecturas críticas sobre el territorio.

Al tener como objetivo potenciar los procesos creativos de los jóvenes al autorreferenciarse fotográficamente con su entorno, se aplicó una guía gráfica de elementos que permitieron a los jóvenes del Kilómetro 41 desarrollar posturas críticas sobre su territorio. Para esto fue necesario desarrollar laboratorios de fundamentación y prácticas creativas para el análisis de la fotografía como medio de integración social, permitiendo así configurar una guía de elementos creativos donde se aplicaron instrumentos etnográficos de observación participante (Alberich et al., 2009; Gutiérrez \& Delgado, 1995). 
A partir de estas interpretaciones, se revisaron diferentes argumentos y reflexiones teóricas que permitieron comprender los fundamentos de las posturas críticas de los y las jóvenes al crear autorretratos. En estas condiciones el autorretrato fotográfico se interpreta como una plataforma creativa que se exploró a través de su condición autorreferencial (Mitchell, 2009). Los y las jóvenes, al observar reflexivamente el territorio y autorretratarse en él, configuraron una guía de elementos creativos que les permitió visibilizar su identidad a través de una determinada agencia social (Díaz-Barriga et al., 2019).

Sobre las anteriores características se identificó que la creación de autorretratos fotográficos son acciones comunicativas autorreferenciadas socialmente, lugar donde la etnografía (Pardo, 1991; Reygadas, 2014) se convierte en la base de un proceso expresivo en el cual intervienen artefactos culturales que hacen posible explorar las características del territorio (Díaz-Barriga et al., 2019). Los y las jóvenes, al relacionar tecnologías y posturas críticas del territorio para crear significaciones y representaciones visuales, transformaron el signo fotográfico en códigos culturales de acuerdo a las apreciaciones propias, como su curiosidad y creatividad.

En consecuencia, el signo fotográfico es entendido como el producto de un sistema convencional donde el joven, a través de la reinterpretación de signos, construye significados visuales sobre los modos de habitar el territorio, integrando significados del entorno. Sobre estas condiciones, se reconocen las operaciones retóricas que afectan su proceso creativo, es decir, en la manera como el joven se apropia de diferentes significados y tecnologías. Las anteriores inferencias permitieron el desarrollo de nuevas relaciones teóricas, donde se relacionó el análisis de la creación fotográfica a través de cuatro líneas fundamentales:

a. La semiótica de la imagen: la semiótica (Morris, 1985; Peirce ,1987) es tomada como una línea fundamental basada en el lenguaje de la imagen y la comunicación visual (Acaso, 2011).

b. La retórica visual: a través del trabajo de campo se identificó la evolución del autorretrato al selfie-media como los rasgos culturales de un artefacto que, a través del efecto intencionado del creador, adquiere una gran relevancia desde su estatuto retórico (Buchanan, 1985, 1990; Gamonal, 2011; Goodnow, 2016), en el sentido que los y las jóvenes crean piezas comunicacionales y construyen a través del autorretrato fotográfico narrativas basadas en posturas críticas hacia el territorio. 
c. La postura crítica del territorio basada en el pensamiento crítico (en adelante PC) y la pedagogía visual: son los componentes de un trabajo de campo donde las tecnologías de la información y el desarrollo del PC (Facione, 2007; Patiño, 2014; Walsh, 2005) hacia el territorio, se convirtieron en la base del artefacto cultural que depende del desarrollo de habilidades, destrezas y entrenamientos fundamentados principalmente por la pedagogía visual (López \& Villa, 2017). Su propósito era facilitar los procesos de creación de autorretratos fotográficos.

d. La fotografía como artefacto comunicativo: es la relación comunicativa dada entre humanos y artefactos. Los y las jóvenes comprenden la fotografía como un dispositivo con el cual se explora el uso de la tecnología como lenguaje (Brea, 2002). Por lo tanto, se analizaron teorías de modelos comunicativos de la información visual (Lévy, 2004; Manovich, 2006; McLuhan \& Powers, 1995) con el objetivo de plantear un esquema de principios creativos necesarios para la creación fotográfica.

Las anteriores líneas fundamentales de investigación permitieron obtener información necesaria para comprobar la relevancia de los elementos creativos que desarrollaron los y las jóvenes del Kilómetro 41 al producir autorretratos fotográficos. Estas condiciones propiciaron entablar la siguiente pregunta: ¿es posible comprobar la relevancia de una guía de elementos creativos en diseño fotográfico para poner de manifiesto los modos de habitar de los jóvenes y las jóvenes?

Los temas abordados permitieron comprender que la creación fotográfica, el diseño y la tecnología son componentes de una línea de pensamiento donde la literatura es escasa; sin embargo, los diferentes puntos de vista relacionados son suficientes para delimitar un camino hacia el análisis, el cual busca proponer y comprobar un esquema de elementos creativos que disponen generar nuevas relaciones teóricas (Hernández et al., 2014). En la condición que se analizan documentos, posturas y pensamientos para comprender los elementos del PC en los jóvenes y las jóvenes, la creación fotográfica se transformó en un artefacto de la comunicación que permitió, a través del trabajo de campo, estructurar, navegar, programar y representar autorretratos fotográficos. Con el fin de desarrollar habilidades para la manipulación de conceptos y tecnologías, los y las jóvenes expresaron memorias, reencuentros con el territorio, experiencias en comunidad y relatos de diferentes modos de habitar el Kilómetro 41. 


\section{Creación del signo fotográfico diseñado con base en procesos semióticos del lenguaje visual}

En una situación donde el razonamiento lleva a los y las jóvenes al desarrollo de posturas críticas, se explora el autorretrato fotográfico como plataforma que permite recuperar memorias del territorio. En este marco, se reconoce que todo sistema de representación fotográfica es el producto de un acto de semiosis y de la configuración del lenguaje visual, en tanto que los imaginarios de reconciliación con el territorio son autorretratos fotográficos que adquieren sentido a través de su instauración como código cultural; así, se comprende el signo fotográfico como una línea fundamental del lenguaje visual y la comunicación que permite ser analizada desde la tradición semiótica desarrollada por Morris (1985) y Peirce (1987). Con Morris (1985) se reconoce que el representamen solo es posible a través del acto de semiosis que se instaura por su vehículo sígnico (pp. 27-29); por su parte, con la lógica semiótica de Peirce (1987) se infiere que este vehículo sígnico corresponde a la capacidad comunicativa humana para referenciar significados indíciales, icónicos y simbólicos (p. 249).

En tanto que el signo fotográfico puede ser documental, gráfico o artístico, en cada género media un problema centrado en el lenguaje de la comunicación visual. Estos aportes permitieron introducir los conceptos desarrollados por Acaso (2011), quien, al reconocer la tradición semiótica, propone el lenguaje visual como un código específico de la comunicación, lugar donde la semiótica visual es una rama del saber centrada en los problemas comunicativos del lenguaje visual (pp. 23-25). En este sentido, se reconoce el autorretrato fotográfico como la construcción de un signo capaz de autorreferirse visualmente a través de procesos etnográficos, pedagógicos, reflexivos, narrativos y retóricos.

\section{El autorretrato fotográfico basado en el artefacto culltural, la retórica y la autorreferencia}

El Kilómetro 41 se considera como un lugar abierto a la reflexión con jóvenes que desarrollan habilidades para percibir reflexivamente la realidad de su territorio con el fin de llevar a cabo procesos creativos (Torres et al., 2017).

En este marco, se hace uso de la creación de autorretratos fotográficos para acercarse a procesos de interpretación de la memoria y la realidad. Como lo manifiesta Sontag (2006) «aprendemos a vernos fotográficamente» (p. 125); según la autora, se considera que la fotografía es un acto creativo que permite explorar el universo y darlo a conocer. 
Los y las jóvenes, al salir a recorrer territorios bajo la excusa de fotografiarse, pueden descubrir verdades y falsedades. La fotografía se convierte en una herramienta objetiva para documentar la realidad social que los rodea.

El reconocimiento de los lugares como acto reflexivo ha ido desapareciendo en los hábitos de los y las jóvenes, quienes muestran indiferencia ante el pensar, construir y recorrer los territorios. Ellos, al observar el territorio, reconocen memorias y maneras de habitar la cotidianidad. Así, la producción creativa entra en un diálogo entre acciones etnográficas y el uso de tecnologías para la expresión visual. En esta línea, Reygadas (2014) manifiesta que todos somos etnógrafos por la capacidad de describir la cultura; así como también por la posibilidad que tiene el hombre de analizar procesos sociales y culturales, pues las sociedades pertenecientes a diferentes contextos están en la potencialidad de hablar sobre lugares y acontecimientos, como una acción etnográfica donde el investigador y el nativo propician espacios para la lectura de territorios (pp. 92-95).

Teniendo en cuenta que la creación fotográfica y el autorretrato son ejercicios de composición entre el cuerpo y el espacio, se comprenden también como ejercicios narrativos de comunicación. En estos espacios se percibe la retórica de la imagen como la acción creativa que amplía las maneras de representar y dar cuenta de las percepciones que orientan la lectura de lugares que llaman la atención. Cuando se autorretratan de manera libre, se pone de manifiesto el querer, el sentir, el interés, los recuerdos y las percepciones sobre sí mismos y sobre el territorio.

Al hacer una pausa para indagar cómo los jóvenes se piensan ante la comunidad y representan lugares comunes, se comprende la memoria como parte de un proceso de organización donde los espacios ocupados se transforman en lugares habitados y habitables. Sin importar el tiempo que llevan en los mismos sitios, surgen percepciones ingenuas que Pardo (1991) describe como la indiferencia con la que se capta un lugar antes de experimentarlo, porque solo el que ha podido alcanzar el «acontecimiento espacial» podrá superar el sentirse extraño (pp. 148-149). Por lo tanto, la creación fotográfica busca abolir la indiferencia de los y las jóvenes cuando captan la realidad de su mundo para hacer visible lo invisible e interpretar imaginarios del territorio. En este sentido, la retórica y el uso de técnicas fotográficas tomaron un papel fundamental para el desarrollo de las actividades donde los estudiantes combinaron registros fotográficos y relatos sobre percepciones del lugar para lograr el acontecimiento. 


\section{Del autorretrato fotográfico a la selfie como artefacto cultural}

Después de casi dos siglos de nacimiento, la fotografía se reconoce como un dispositivo de repercusión social, en el sentido que el retrato evolucionó a través de la fotografía como el principio de un proceso democrático; esta se enmarcó en un derroche inventivo de dispositivos periféricos, formatos y resoluciones que han sido accesibles a casi todas las comunidades y esferas públicas. Dicho proceso democrático permitió discernir cómo los dispositivos móviles se convirtieron en tecnologías de registro visual que permitieron el desarrollo del PC y la experiencia visual de estudiantes que tenían como objetivo desarrollar autorretratos fotográficos. Sobre lo anterior, Díaz-Barriga et al. (2019), al analizar el pensamiento y la experiencia en estudiantes de secundaria en situación de vulnerabilidad, sostienen que el uso de artefactos culturales es crucial para autoexpresarse y autodefinirse, en el sentido que los escolares se relacionan con instrumentos que emplean a diario como mediación del pensamiento y la actividad (p. 243). Esta reflexión posibilitó interpretar la creación fotográfica como un artefacto cultural donde los y las jóvenes, al hacer uso de cámaras de dispositivos móviles, relacionaron significados visuales y tecnologías para autorreferenciarse con su entorno. Como lo plantea Susperregui (1987), no importa la calidad, sino la cantidad de lugares y momentos elegidos por los fotógrafos para pulsar el botón (p. 193). Gracias a estos avances, los individuos están en la capacidad de autorretratarse y capturar su entorno para transmitirlo a discreción, convirtiendo a cada individuo en «emisor y receptor de sus propios mensajes» (p. 194).

Al tener presente la evolución del autorretrato fotográfico y su significado en la actualidad, se evidencia en la mayoría de los y las jóvenes una transformación del autorretrato que emerge a una supremacía del yo self media, como una especie de autorreferencia fotográfica. Esta se centró en explorar diferentes lugares y transformaciones de la identidad, donde el joven, a través del acto de autorretratarse, relaciona la técnica fotográfica a través de metáforas que cuestionan la memoria y el habitar como elementos necesarios para trascender el simulacro de pertenecer.

\section{Sobre la retórica como intención creativa del self-media}

Goodnow (2016), al realizar un análisis sobre la selfie, enfatiza que en la actualidad los críticos han comenzado a examinar todo tipo de artefactos a través de su importancia retórica (pp. 124-126). El análisis de esta presunción significó comprender la retórica desde su efecto intencional (Buchanan, 1990). Esta intención es explicada por Buchanan 
(1990) para referirse al pensamiento del diseño. Al extrapolar este concepto a las bases de la investigación, se interpreta que la intensión creativa del creador fotográfico está basada en un estatuto retórico de simbolización que se refiere a una forma de pensamiento fotográfico, como producto de una relación entre conceptos y tecnologías que comunican y representan el mensaje visual (autorretrato y self-media). Desde otra perspectiva, Buchanan (1985), en su Declaración por el diseño, explica que una teoría apropiada sobre la retórica en el diseño es un cuerpo de conceptos donde la tecnología se convierte en un problema retórico integrado al diseño (p. 4). En este sentido, un problema retórico integrado a la creación fotográfica es lo que propone Belting (2007) al argumentar que las imágenes fotográficas simbolizan la percepción y el recuerdo del mundo a través de la interacción entre imagen y medio: el medio es una invención técnica y la imagen es el sentido simbólico del medio (p. 265). Otra forma de explicar el asunto de la retórica se hace evidente en la pedagogía visual. Gamonal (2011), al aplicar la retórica en la enseñanza del diseño gráfico, explica que las operaciones y las figuras retóricas cumplen un papel fundamental como elementos detonantes de creatividad, en la condición que un diseño parte de la creación de un discurso persuasivo dirigido a un público determinado para influenciar una acción (p. 410). Se comprende así que la creación de un autorretrato fotográfico es una construcción retórica que depende de procesos pedagógicos; es un artefacto cultural de producción creativa que se origina a través de un acto intencionado de manipulación y transformación del signo fotográfico aprehendido y autorreferenciado socialmente.

\section{El autorretrato fotográfico desde su estatuto autorreferencial}

Comparar el desarrollo del autorretrato fotográfico a través de una retórica de la selfie se acerca al concepto de autorreferencia planteado por Mitchell (2009). Este la argumenta desde una estética posmoderna, como la creación que se vuelve autoanalítica y se dirige a las condiciones que determinan su situación institucional (p. 39). El argumento lleva a pensar la autorreferencia como un modelo creativo que permite la visibilización del yo y de los lugares a través del autorretrato fotográfico, como una producción creativa que desarrolla el PC y la representación de mensajes visuales sobre el territorio.

Así, la intención creativa del autorretrato fotográfico integra la memoria visual y la reconciliación con los territorios. Como lo plantea Bloomfield (2015, como es citado por McCandless), la reconciliación debe estar orientada a la transformación y construcción de relaciones (p. 14). Los jóvenes y las jóvenes del Kilómetro 41, procurando un espacio 
de reconciliación con el territorio, no solamente piensan en la apariencia estética de la foto a través de un estatuto autorreferencial, sino que también invitan a pensar los lugares, a resignificarlos a través de la palabra y del gesto creativo de la imagen, resaltando los espacios para pasar de la fase de indiferencia a la apropiación y conciencia del habitar en determinada comunidad (Pardo, 1991).

\section{La postura crítica del territorio fundamentado en el PC y la pedagogía visual}

La creación fotográfica —investigada en este contexto- se desarrolló desde dos relaciones estructurales:

a. El PC en jóvenes del Kilométro 41, capaces de proponer posturas críticas del territorio a través de la creación de autorretratos fotográficos.

b. Las actividades de pedagogía visual que permitieron a los y las jóvenes desarrollar técnicas, destrezas y habilidades para la producción de autorretratos fotográficos.

En el sentido que los y las jóvenes desarrollaran posturas críticas sobre el territorio, se reconoce el PC como la capacidad para organizar y juzgar la información disponible. Lo anterior permite seguir a Walsh (2005), quien presenta al PC como la afirmación del derecho de pensar a partir de la propia experiencia, en lugar de adaptarse a las circunstancias dadas en su contexto (p. 8). En esta relación se encuentran en juego experiencias que permiten a los jóvenes tomar diferentes posturas sobre el territorio, convirtiendo la fotografía en un medio de registro y documentación.

En este contexto la creación fotográfica es un medio creativo que depende de procesos argumentativos basados en el habitar, la memoria y la adquisición de nuevas experiencias visuales. En esta línea, según Patiño (2014) el PC es un recurso poderoso para la vida personal. Cuando el autor retoma conceptos de Facione (2007) identifica al PC desde el examinar, identificar, analizar y evaluar las razones que apoyan y contradicen una argumentación (pp. 6-7). Esta inferencia propone un eje fundamental de investigación, en el que se identifica la estructura de un contexto donde los y las jóvenes aceptan y crean nuevos argumentos usando creaciones fotográficas.

Los argumentos de Facione (2007), Patiño (2014) y Walsh (2005) representan un contexto centrado en el ejercicio de la comunicación y la lógica verbal. En este sentido, una lógica argumentativa del PC se valora por las competencias y habilidades desarrolladas a 
través de la pedagogía visual. Es de reconocer cómo López y Villa (2017) amplían este concepto como la necesidad consciente para el desarrollo del PC en estudiantes de diseño gráfico. Los autores proponen la alfabetidad visual como una destreza que alude al desarrollo de diferentes competencias visuales de las personas cuando observan e integran experiencias sensoriales, permitiéndoles observar objetos o símbolos del entorno (p. 178). Sobre lo anterior, enfatizan en la necesidad de hacer explícitas las actividades que pueden promover el desarrollo de la alfabetidad visual, con la intención de que el estudiante haga consciente el desarrollo de sus piezas comunicacionales (p. 191).

Por esto, la creación fotográfica se convirtió en una herramienta pedagógica que permitió a los y a las jóvenes escolares explorar la memoria y configurar habilidades para representar el PC de imaginarios del territorio autorreferenciados socialmente. De esta manera, vinculando situaciones relevantes para la vida, se tiene la capacidad de integrar en los procesos argumentativos a la identidad y a la experiencia. Como lo plantean DíazBarriga et al. (2019), cuando se habla de adolescentes se alude a la configuración de su identidad y los valores de una agencia social que permite apropiar o rechazar conocimientos en diferentes condiciones institucionales (p. 242). Los y las jóvenes empiezan a tener una forma diferente de pensar y de poner en manifiesto su propio estilo de vida (Jiménez, 2015, p. 437).

\section{Modelos comunicativos basados en la creación fotográfica y el PC como artefacto cultural}

Explorar la creación fotográfica como artefacto cultural se conecta con los argumentos que plantea Brea (2002) al considerar que la tecnología es lenguaje; un análisis histórico de las formas sería inabordable sin la articulación de los dispositivos tecnológicos que simbolizan el mundo con lo real (p. 18). Brea propone así un problema de la comunicación dado entre la tecnología y el lenguaje, el artefacto y la producción simbólica de informaciones que adquieren sentido. Esta inferencia se convirtió en un concepto clave que abrió la ruta para interpretar la producción creativa del signo fotográfico desde dos problemas concretos: el proceso de representación basado en el PC y las tecnologías de producción visual como mediaciones que integran conceptos sociales con acciones creativas.

La creación fotográfica, como artefacto cultural, propone una nueva ruta de investigación que busca comprender los principios creativos necesarios para la producción de mensajes visuales. Sobre este marco, se analizaron teorías y principios comunicativos desarrollados por Lévy (2004), Manovich (2006), McLuhan y Powers (1995). 
McLuhan y Powers (1995) proponen el tétrade como un modelo comunicativo basado en la lógica lingüística y estructurado en cuatro partes. Los autores postulan la posibilidad que este modelo sirva para estudiar el impacto de las tecnologías sobre la sociedad. Durante el desarrollo de su investigación descubrieron la estructura del tétrade, donde todas las formas de comunicación:

(a) intensifican algo en una cultura, (b) vuelven obsoleta otra, (c) recuperan una fase o factor dejado de lado desde tiempo atrás y (d) sufren una modificación (o inversión) cuando se las lleva más allá de los límites de su potencial. (p. 16)

McLuhan y Powers (1995) logran metaforizar un modelo abierto a la interpretación del efecto de las tecnologías en los sistemas de la comunicación. El tétrade es una metáfora de la aldea global, así como un modelo que sirve para comprender el desarrollo del artefacto en la cultura, el territorio y la comunicación a finales del siglo XX.

Esta metáfora hace considerar la creación fotográfica como un artefacto de la comunicación que sirve para estudiar la acción creativa desde sus componentes imaginarios, tecnológicos e iconográficos. Cuando el PC involucra tecnologías y expresiones, la creación fotográfica - sea documental, gráfica o artística - se comprende como modelo de producción tecnológica basada en la observación y la significación social.

La observación, el signo fotográfico, la tecnología y el lenguaje visual son los elementos clave que potenciaron habilidades y pensamientos de un saber colectivo adquirido socialmente. El anterior concepto introduce al estudio del modelo comunicativo desarrollado por Lévy (2004), quien argumenta que el saber está atravesado por cuatro espacios antropológicos (la tierra, el territorio, la mercancía y el saber) generados por la operación imaginaria y la práctica de millones de humanos que usan máquinas antropológicas transversales, las cuales intervienen la esencia organizacional de las instituciones (p. 85). En este contexto, se interpreta la creación fotográfica como una máquina antropológica transversal, que depende del uso de programas y artefactos que promueven la pedagogía visual y la postura crítica hacia el territorio, como un medio donde los sujetos relacionan la tecnología y el pensamiento para obtener un conocimiento más amplio del entorno.

Para ampliar las anteriores perspectivas comunicativas, se relacionaron otros modelos comunicativos direccionados a reconocer, en sus principios teóricos, las condiciones comunicativas del creador fotográfico inmerso en una cultura digital. Sobre esta situación, Manovich (2006) plantea las características de los nuevos medios de la comunica- 
ción a través de cinco principios: la representación numérica, la modularidad, la automatización, la variabilidad y la transcodificación cultural. Estos principios son relacionados por el autor como elementos comunes que coexisten en la interacción de los usuarios con los medios tradicionales y los nuevos medios de la comunicación (pp. 8-20).

Los modelos analizados permitieron demostrar que los componentes comunicativos y expresivos están integrados principalmente por la producción y la tecnología de contenidos visuales, donde los sujetos son capaces de integrar el cuerpo, el artefacto y el territorio para configurar la experiencia creativa del mensaje visual. Por lo tanto, el uso de técnicas fotográficas, tanto digitales como análogas, tomaron un papel fundamental para el desarrollo de actividades desarrolladas en el trabajo de campo.

\section{Metodología}

Este artículo se fundamenta en inferencias abductivas desarrolladas a través de medios documentales y experimentales de creación, donde 11 estudiantes de bachillerato (entre los 14 y 19 años de edad), carentes de formación académica en fotografía y comunicación visual, se convirtieron en sujetos de estudio. Los conocimientos aportados en este informe son de carácter exploratorio y analítico. Se muestran evidencias iconográficas, las cuales describen la producción y la autorreferencialidad del autorretrato, como una acción creativa que permitió representar mensajes fotográficos para la reconciliación de los y las jóvenes con el territorio.

Primero se revisaron teorías y conceptos sobre modelos de producción creativa y comunicación, sustentadas a través de la investigación cualitativa, como el análisis de documentos, posturas y pensamientos que permiten crear nuevas relaciones teóricas (Hernández et al., 2014, p. 8); ello facilitó comprender los procesos autorreferenciales sobre memoria visual y poéticas de reconciliación. Por tanto, la pedagogía visual, las posturas críticas hacia el territorio y las tecnologías de producción constituyeron la creación de signos fotográficos.

Posteriormente, se aplicaron instrumentos de observación participante que, de acuerdo con Gutiérrez y Delgado (1995), son métodos empíricos y etnográficos del análisis de la información visual (p. 143). Alberich et al. (2009) argumentan que, más que una técnica sistematizada, la observación participante es una actitud presente en todo el proceso de la investigación; recomiendan no dejar escapar detalles, tomar notas sencillas relativas 
al lugar, personas, hechos y circunstancias a través de una recolección de datos e informaciones que complementan una visión general de la actividad realizada (p. 36). A través de las anteriores características, se diseñaron laboratorios de fundamentación sobre los elementos creativos y se desarrollaron talleres pedagógicos sobre memoria, creación fotográfica y comunicación visual. Para comprobar la relevancia de los elementos creativos se propuso, a través de una guía gráfica, direccionar a los y las jóvenes a un entorno controlado de creación, donde la observación participante permitió reconocer los rasgos particulares de los elementos creativos que posibilitaron el desarrollo del PC y de la representación visual.

Posteriormente, sobre la información recolectada en el trabajo de campo se aplicaron herramientas de evaluación. Hernández et al. (2014) define esta tarea como un instrumento de investigación (p. q) que, al ser aplicado a través de encuestas a los participantes, permitieron evaluar la relevancia de la aplicación de elementos de creación fotográfica, habilitando así la interpretación de datos reales para valorar nuevas perspectivas sobre su utilidad.

\section{Observaciones éticas}

El trabajo de campo empírico se pactó a través de un consentimiento informado, con lo cual se dio a conocer tanto a los estudiantes como a sus acudientes los objetivos y alcances del proyecto. Dado que la mayoría de los estudiantes eran menores de edad, este consentimiento fue firmado por los padres o acudientes responsables. ${ }^{1}$

\section{Modelación de los elementos creativos en diseño fotográfico}

Producto de una triangulación entre conceptos y relaciones teóricas se reconocieron las bases para sintetizar los principios, niveles o elementos necesarios para representar mensajes fotográficos. Sobre la hipótesis que esboza que toda fotografía es el producto de un sistema de creación desarrollado a través de procesos semióticos, retóricos y tecnológicos, se originó una nueva relación teórica, de la cual se plantea la primera versión de un modelo creativo en diseño fotográfico basado en cinco principios (figura 1).

\footnotetext{
${ }^{1}$ En este compromiso ético los investigadores dejaron claro que la información solo se utilizaría con fines académicos; por lo que se reservó el derecho de la publicación de imágenes y el uso de los nombres de los participantes y de las entidades educativas involucradas.
} 
Figura 1

Principios en la acción creadora en diseño fotográfico

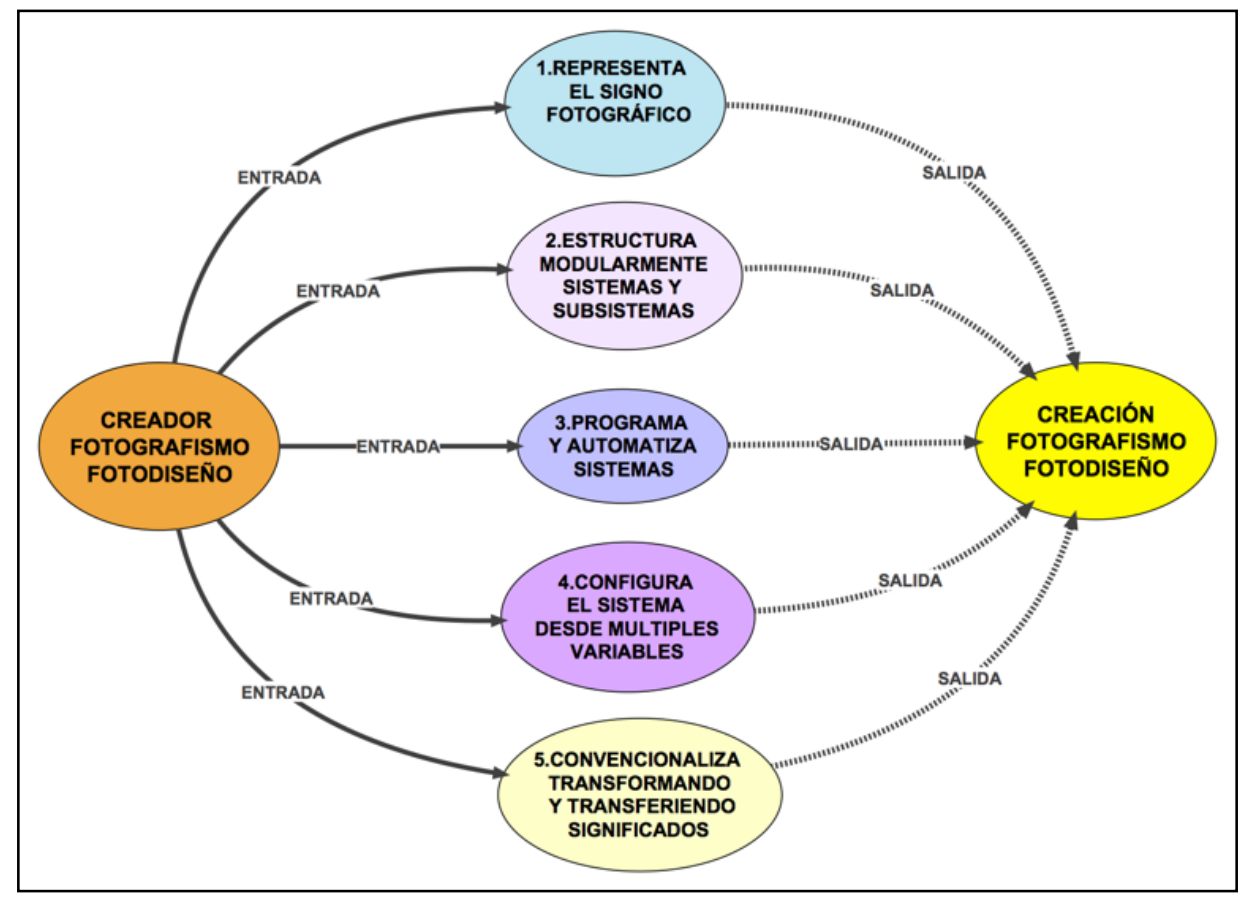

Nota. Esquema versión 1.o.

Con la idea de comprobar empíricamente los principios creativos consignados en el anterior esquema, se propuso la realización de un trabajo de campo piloto que permitiera aplicar instrumentos de observación participante y evaluar los principios creativos. Para ello se realizó en el 2017 un trabajo de campo con 27 estudiantes de primeros semestres de Diseño Visual de la Universidad de Caldas.

La evaluación de este trabajo de campo permitió sintetizar y reestructurar los principios creativos a partir del problema de la observación y la navegación del territorio. Estos resultados posibilitaron plantear una nueva versión de los principios creativos relacionados en el desarrollo de un nuevo esquema (figura 2), donde se comprendieron los elementos que permiten el uso de tecnologías y la observación crítica del fenómeno social del territorio. La anterior reestructuración evidenció que los y las jóvenes, al navegar estas características, recurrieron a la memoria y la atención, en el sentido que la facultad de observar y navegar el territorio les confirió los elementos necesarios para estructurar, programar y ensamblar la representación del mensaje visual. 
Figura 2

\section{Elementos de la acción creadora en diseño fotográfico}

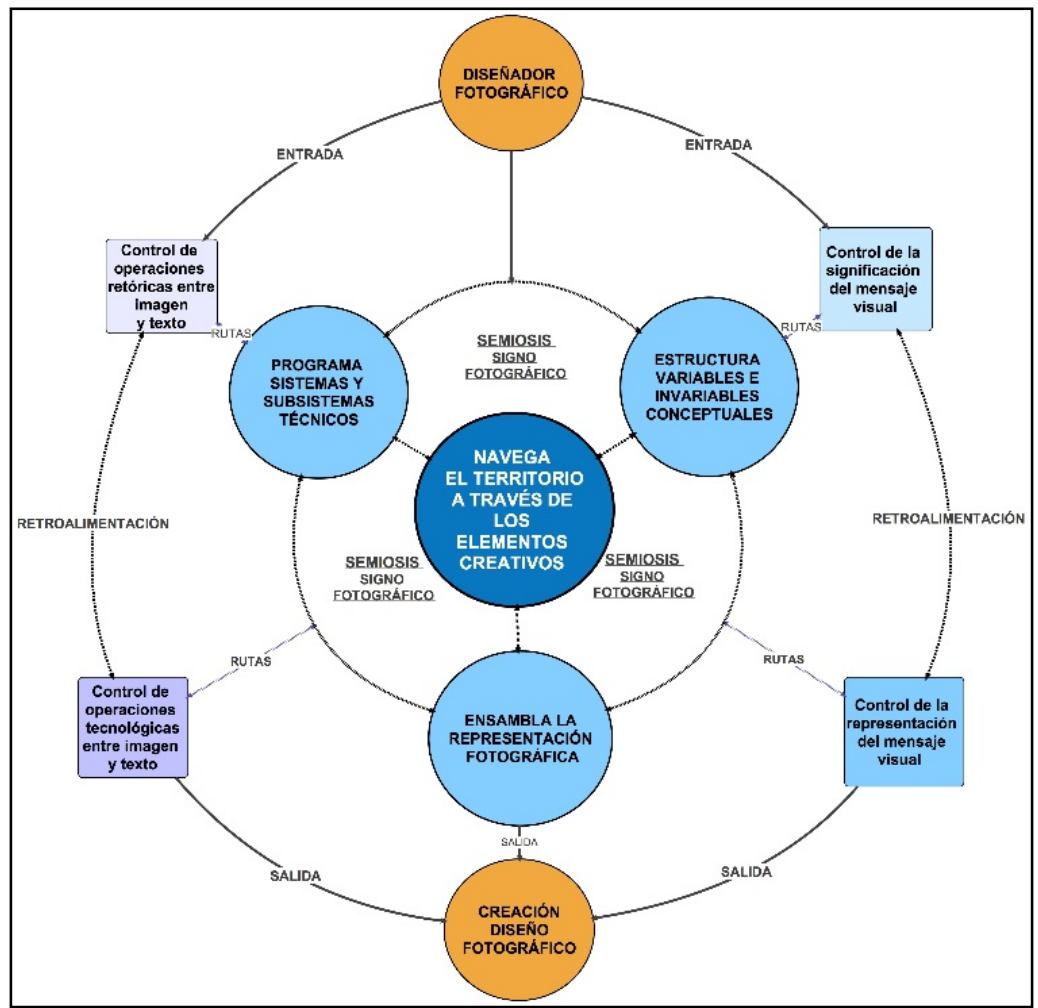

Nota. Versión 2.0

Para comprobar los elementos creativos del nuevo esquema, se buscó desarrollar un nuevo trabajo de campo enfocado a ampliar las posturas críticas de los y las jóvenes de la Institución Educativa Rural Giovanni Montini. Se cree que el diseño fotográfico es en este trabajo de campo un sistema creativo donde se integra la memoria, los modos de habitar y la reconciliación con el territorio; concepto central de esta investigación que correlaciona la creación fotográfica con la autorreferencialidad, las cuales permiten ampliar las posturas críticas de los y las jóvenes que habitan el Kilómetro 41.

\section{Resultados}

Los resultados de esta investigación, producto del análisis y la instrumentación de herramientas metodológicas, permitieron analizar los procesos creativos de un grupo de jóvenes estudiantes de bachillerato en un espacio controlado de creación, en el cual los 
lugares habitados se percibieron y representaron a través de autorretratos fotográficos. En dichos lugares se evidenciaron los intereses de los y las jóvenes por relacionar el acto creativo a través de la observación del territorio y los modos de habitarlo. Se comprendió que, al navegar el territorio, los y las jóvenes registraron a través de la lente fotográfica nuevos aspectos de la memoria y el habitar; por lo tanto, el desarrollo del nuevo esquema aplicado en el trabajo de campo, deja reconocer cómo los elementos creativos (estructurar, navegar, programar y representar) se convirtieron en un proceso pedagógico que les posibilitó potenciar el desarrollo del PC y el uso de diferentes tecnologías que fueron necesarias para la creación de autorretratos fotográficos.

\section{Estructura variables e invariables conceptuales}

Los y las jóvenes, al percibir y al hacer consciente su mundo visible, entraron en un estado de interpretación y significación subjetiva. Este proceso comunicativo es producto del acto de semiosis donde se estructura el signo fotográfico a través del ejercicio de observación e intención representativa del mensaje visual (figura 3). Así, este acercamiento permitió referenciar dos tipos de acciones estructurales:

a. Una acción pedagógica de la comunicación visual que permite a los participantes conectar las actividades de los laboratorios de fundamentación con talleres de prácticas creativas.

b. Una acción consciente del PC que permite a los participantes examinar ideas e identificar argumentos por medio de variables conceptuales basadas en la memoria y el habitar el territorio.

\section{Figura 3}

Acción: estructurar variables e invariables conceptuales

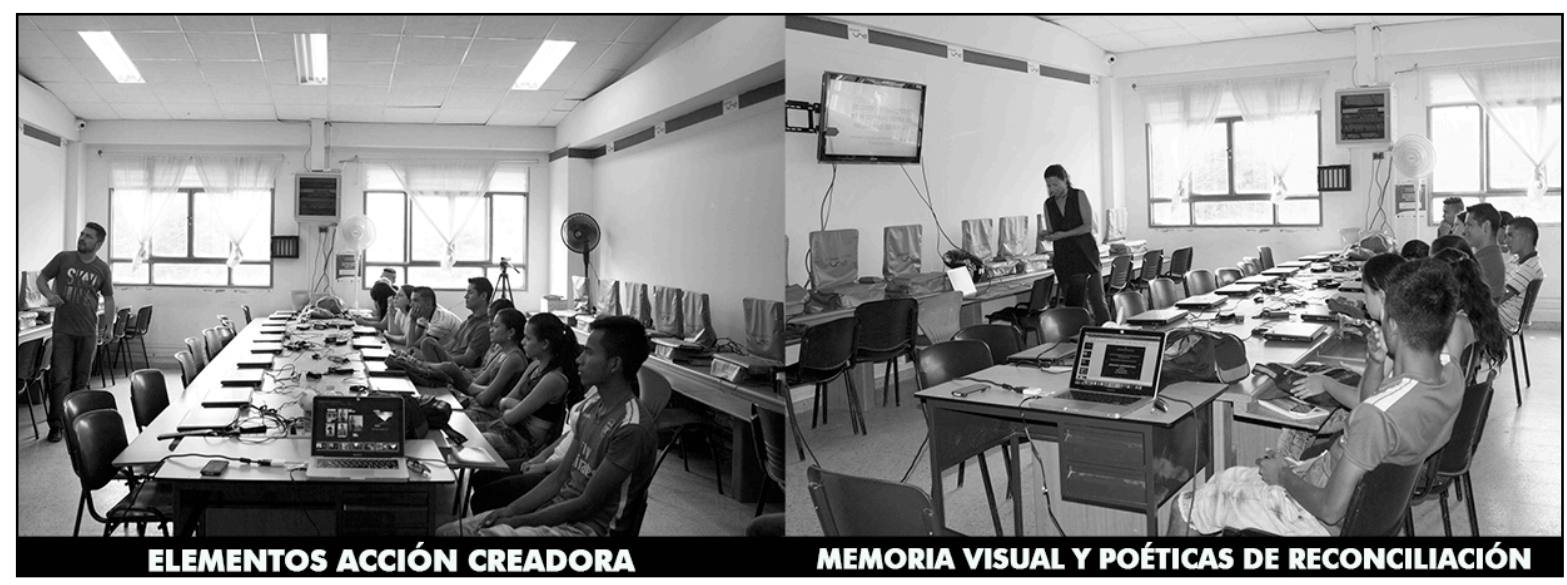


Cuando se pide a los y las jóvenes observar el entorno para autorretratarse en él, se encuentran inmersos en un laboratorio experimental de organización de conceptos visuales definidos a través de operaciones técnicas y retóricas que permiten narrar y representar autorretratos fotográficos. Este elemento permitió a los y las jóvenes implementar procesos estructurales de la pedagogía visual para conectar lugares, emociones, recuerdos y significados a través de la interpretación de signos sociales. En este marco, la estructuración es en principio la acción creativa donde el joven, por medio de un acto de semiosis, pudo estructurar informaciones visuales, argumentos y significados del territorio.

\section{Navega el territorio a través de los elementos creativos}

Se comprende esta acción como el proceso consciente de atención e interpretación de la información visual del entorno; este proporcionó a los y las jóvenes el camino para seleccionar rutas y explorar etnográficamente el territorio. La acción de navegar se reconoce como el elemento central para el desarrollo del PC, en la forma que se convirtió en un instrumento de observación y análisis para identificar lugares y memorias, así como permitió a los y las jóvenes plantear posturas críticas sobre recorridos cargados de sentido.

En las figuras 4 y 5 se relacionan las actividades desarrolladas en una salida de campo grupal que se inició en el Giovanni Montini y terminó en el puente del río Cauca. El objetivo de la salida fue que los y las jóvenes exploraran memorias y se apropiaran de lugares que les permitieran producir autorretratos fotográficos.

Figura 4

Acción: navegar las características del territorio

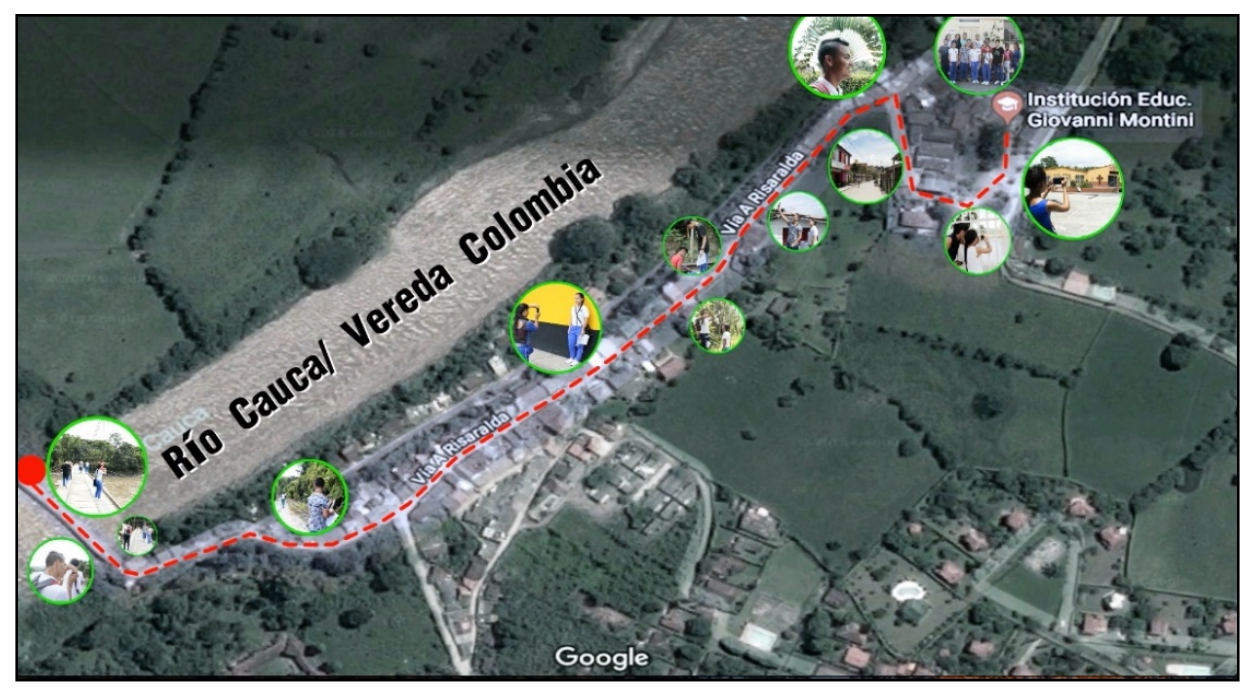

Nota. Mapa provisto por Google Maps. @ 2020 Google. Intervenido. 
Figura 5

Acción: navegar las características del territorio

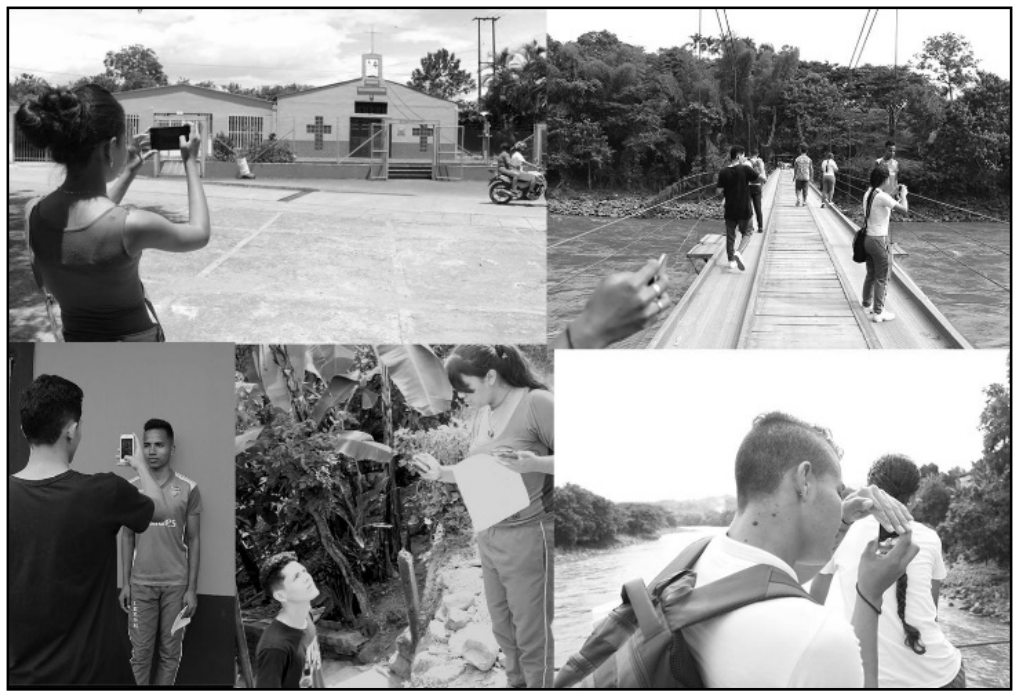

\section{Programa sistemas y subsistemas técnicos}

Es el elemento que permitió a los y las jóvenes la construcción retórica de la imagen por medio de la operación de dispositivos para la manipulación y transformación del signo visual (figura 6). A través de talleres pedagógicos de composición visual y el uso de programas básicos de manipulación digital en dispositivos móviles y computadoras, se solicitó a los participantes que seleccionaran un autorretrato para editarlo y transformarlo digitalmente en escala de grises y posteriormente imprimirlo en papel. Con el fin de revelar la imagen negativa por contacto, se adaptó en la institución un laboratorio de revelado fotográfico a blanco y negro.

\section{Figura 6}

\section{Acción: programar la información visual}

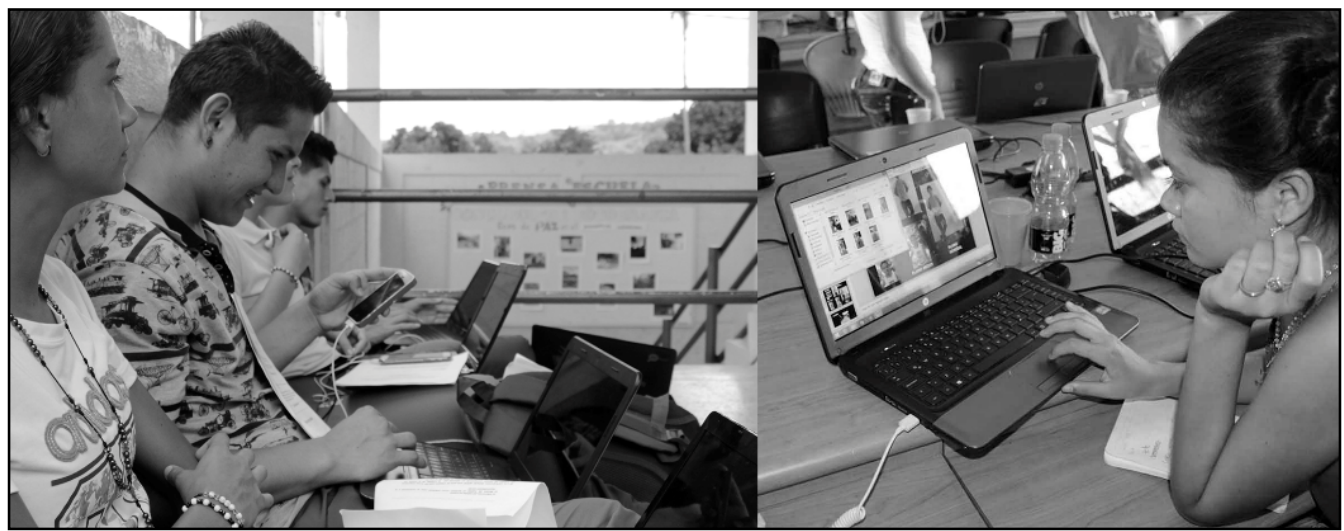

$$
\begin{aligned}
& \text { Rev.latinoam.cienc.soc.niñez juv. Vol.18, No. 3, sep.-dic. de } 2020 \\
& \text { E-ISSN:2027-7679 .https://dx.doi.org/10.11600/1692715x.18304 }
\end{aligned}
$$


A cada participante se le pidió, a través de la técnica del fotograma, intervenir la imagen con la huella de sus manos. El resultado fue una imagen negativa que luego debía ser positivada en un segundo proceso de revelado; posteriormente, se incluía un fragmento de un poema en el cual se reflexionaba sobre el habitar del territorio (figuras 7 y 8 ).

Cuando el creador fotográfico logra un balance entre la técnica y la narrativa del mensaje visual, la programación se convierte en un sistema retórico de transformación que construye sentido. La acción programar hace que el PC sea un espacio para identificar y sustentar la construcción del autorretrato fotográfico, en el cual el uso de la tecnología y las operaciones retóricas están basadas en imágenes y palabras que dan cuenta de la construcción de un lenguaje visual donde los jóvenes habitan y representan su territorio.

\section{Figura 7}

Acción: programar la información visual

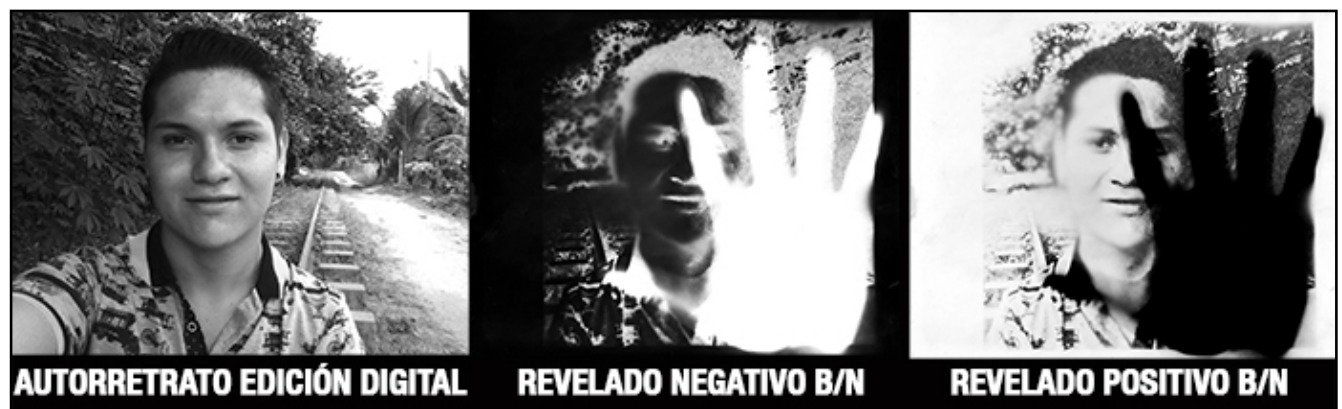

Nota. Primera actividad de proceso de revelado por contacto de negativo y positivado en papel fotográfico blanco y negro.

Figura 8

Segunda actividad de revelado por contacto de huella

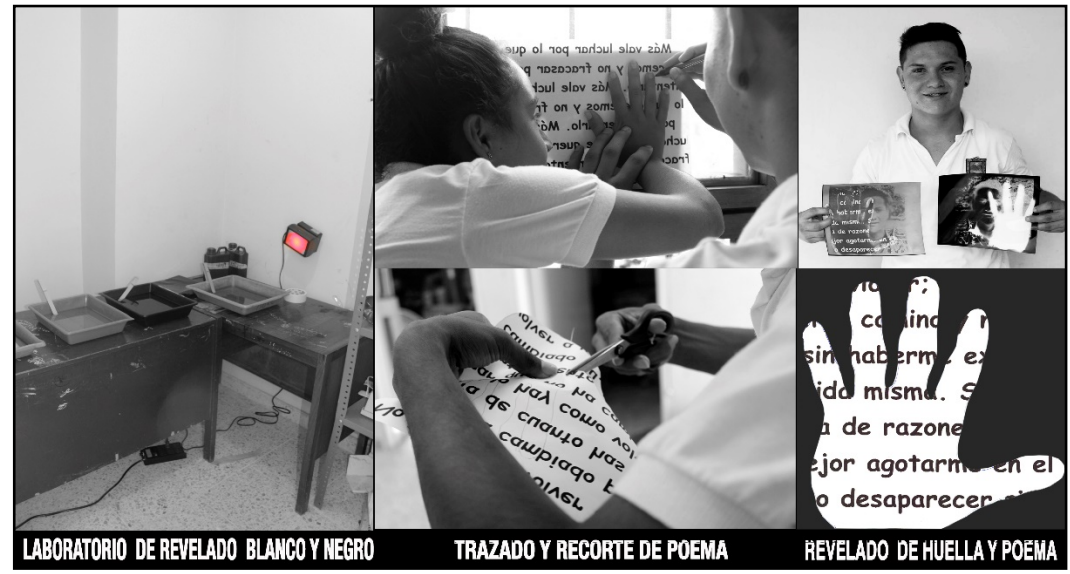

Nota. Recorte de poema y transferencia de la imagen través del laboratorio de fotografía blanco y negro. 


\section{Representa el signo fotográfico}

Se comprende como el resultado visual del signo fotográfico creado a través de un ejercicio retórico de simbolización y autorreferencialidad donde los jóvenes y las jóvenes han ensamblado la representación a través de imágenes y palabras. El autorretrato fotográfico es parte de una relación de elementos creativos donde se representa la creación del mensaje visual (figura 9).

\section{Figura 9}

\section{Acción: representar el mensaje visual}

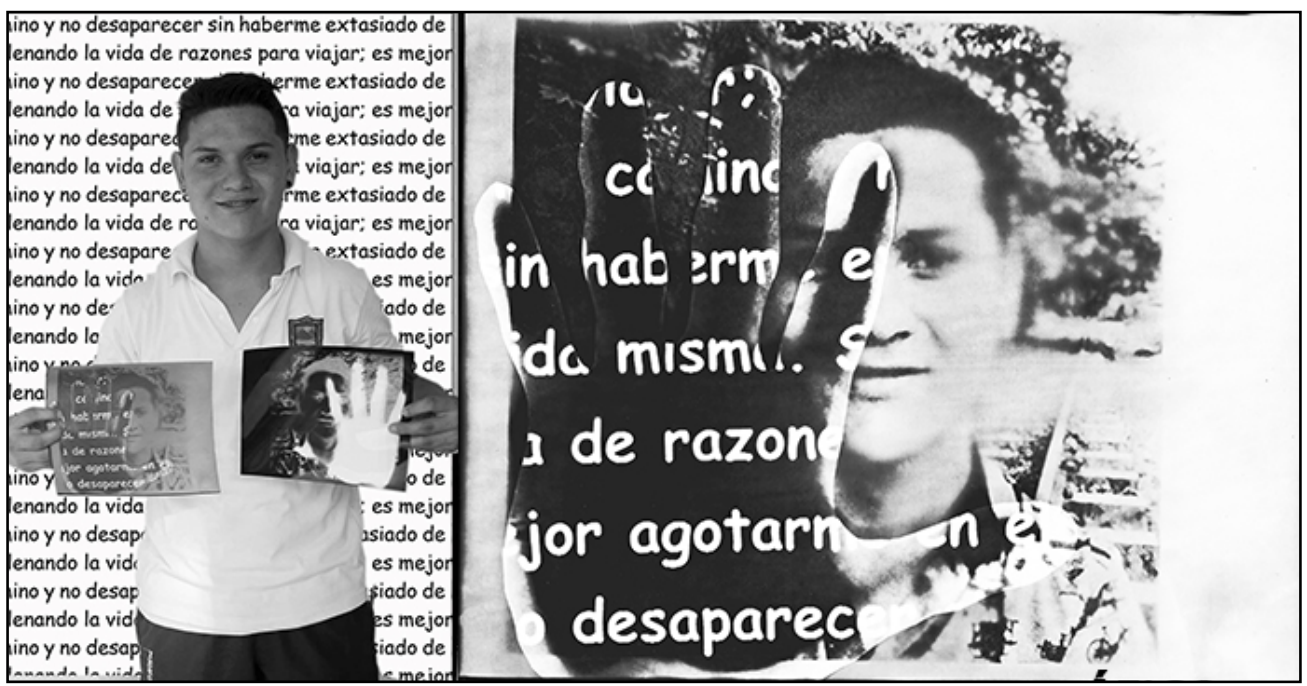

Este elemento comprende la salida de una serie de intercambios y transformaciones de la información visual. Así, la representación es la síntesis de las acciones creativas; es el resultado de una retroalimentación entre la navegación y la transformación de aspectos visuales del territorio que se concluyen a través del pensamiento creativo. El creador propone rutinas de observación y de registro, así como controla variables de significación que han sido estructuradas y programadas a través de sus habilidades. El PC y la tecnología hacen de la representación el resultado de una estructura visual que es programada a través de artefactos e interfaces que permiten la operación retórica del autorretrato fotográfico.

La evaluación de los anteriores elementos creativos propuestos en este trabajo de campo permitieron obtener información clave para comprender los procesos del PC y la producción visual que llevaron a los jóvenes a la creación. La tabla 1 presenta el diseño 
de una ficha de análisis donde se relacionan los resultados obtenidos a través de la creación fotográfica, la retórica, el habitar, la memoria y la reconciliación.

\section{Tabla 1}

Ficha de análisis sobre los resultados de los elementos creativos a través del desarrollo del PC de los jóvenes

\begin{tabular}{|c|c|c|c|c|c|}
\hline \multirow{2}{*}{$\begin{array}{l}\text { Elementos } \\
\text { de la acción } \\
\text { creadora }\end{array}$} & \multirow[b]{2}{*}{$\begin{array}{l}\text { Elementos } \\
\text { del PC }\end{array}$} & \multirow[b]{2}{*}{ Acción retórica } & \multicolumn{3}{|c|}{ Resultado } \\
\hline & & & Habitar & Memoria & $\begin{array}{l}\text { Acto creativo para la } \\
\text { reconciliación con el } \\
\text { territorio }\end{array}$ \\
\hline Estructurar & Organizar & $\begin{array}{l}\text { Estructuraron com- } \\
\text { posiciones fotográfi- } \\
\text { cas a través de la } \\
\text { memoria y el signifi- } \\
\text { cado estético del } \\
\text { cuerpo. }\end{array}$ & $\begin{array}{l}\text { Identificaron su } \\
\text { cuerpo a través } \\
\text { del habitar lugares } \\
\text { y eventos que } \\
\text { construyeron la } \\
\text { história y los ima- } \\
\text { ginarios del terri- } \\
\text { torio. }\end{array}$ & $\begin{array}{l}\text { Estructuraron } \\
\text { recuerdos, signi- } \\
\text { ficados y recorri- } \\
\text { dos de lugares } \\
\text { habitados en } \\
\text { comunidad. }\end{array}$ & $\begin{array}{l}\text { Examinaron (a través } \\
\text { de actividades peda- } \\
\text { gógicas) informacio- } \\
\text { nes sobre el habitar, } \\
\text { la autorreferencia } \\
\text { fotográfica y el terri- } \\
\text { torio. }\end{array}$ \\
\hline Navegar & Identificar & $\begin{array}{l}\text { Observaron el territo- } \\
\text { rio e identificaron } \\
\text { metáforas visuales } \\
\text { para el registro foto- } \\
\text { gráfico. }\end{array}$ & $\begin{array}{l}\text { Documentaron } \\
\text { autorretratos fo- } \\
\text { tográficos a través } \\
\text { del recorrido de } \\
\text { lugares percibidos } \\
\text { conscientemente. }\end{array}$ & $\begin{array}{l}\text { Compararon (a } \\
\text { través de la ob- } \\
\text { servación) memo- } \\
\text { rias del pasado } \\
\text { con nuevas in- } \\
\text { formaciones del } \\
\text { presente. }\end{array}$ & $\begin{array}{l}\text { Interpretaron las ca- } \\
\text { racterísticas del terri- } \\
\text { torio al recorrer y } \\
\text { fotografíar sus cuer- } \\
\text { pos por la ribera del } \\
\text { río Cauca. }\end{array}$ \\
\hline Programar & Construir & $\begin{array}{l}\text { Desarrollaron habili- } \\
\text { dades tecnológicas } \\
\text { para la manipulación } \\
\text { retórica del autorre- } \\
\text { trato fotográfico. }\end{array}$ & $\begin{array}{l}\text { Manipularon rela- } \\
\text { tos fotográficos } \\
\text { sobre el habitar } \\
\text { del territorio. }\end{array}$ & $\begin{array}{l}\text { Construyeron } \\
\text { memorias y pos- } \\
\text { turas críticas del } \\
\text { territorio a través } \\
\text { de la manipula- } \\
\text { ción tecnológica } \\
\text { entre imagen y } \\
\text { texto. }\end{array}$ & $\begin{array}{l}\text { Ensamblaron elemen- } \\
\text { tos fotográficos y } \\
\text { textuales (autorretra- } \\
\text { to y poema) a través } \\
\text { de la experimenta- } \\
\text { ción de procesos } \\
\text { análogos y digitales. }\end{array}$ \\
\hline Representar & Crear & $\begin{array}{l}\text { Ensamblaron autorre- } \\
\text { tratos fotográficos y } \\
\text { poemas sobre el } \\
\text { territorio. }\end{array}$ & $\begin{array}{l}\text { Transmitieron per- } \\
\text { cepciones de } \\
\text { lugares autorrefe- } \\
\text { renciados social- } \\
\text { mente. }\end{array}$ & $\begin{array}{l}\text { Representaron } \\
\text { memorias del } \\
\text { territorio a través } \\
\text { del pensamiento } \\
\text { crítico. }\end{array}$ & $\begin{array}{l}\text { Crearon signos foto- } \\
\text { gráficos autorreferen- } \\
\text { ciales a través de la } \\
\text { aplicación de los } \\
\text { elementos creativos y } \\
\text { las posturas críticas } \\
\text { sobre el territorio. }\end{array}$ \\
\hline
\end{tabular}

En este caso el habitar se relacionó a través de los elementos necesarios para representar el lugar habitado y autorreferenciado fotográficamente, donde la tecnología y la construcción narrativa permitieron documentar y simbolizar posturas críticas del lugar.

Finalmente, el acto creativo de reconciliación buscó que el joven representará el territorio a través de una acción lúdica entre la imagen y el texto. Así, la operación retórica y 
la construcción narrativa permitieron al creador fotográfico aplicar los elementos de producción para autorreferenciarse socialmente.

Como el objetivo del trabajo de campo estuvo centrado en comprender el desarrollo de los elementos creativos y las maneras de habitar de jóvenes a través de la creación de autorretratos fotográficos, se buscó validar los niveles de complejidad de los elementos creativos usados a través de una encuesta desarrollada con 5 preguntas:

a. ¿Las reflexiones expuestas por los profesores en el aula le permitieron comprender conceptualmente los elementos necesarios para la creación de autorretratos fotográficos?

b. ¿La salida de campo que realizó desde la institución G. M. hasta la ribera del río Cauca fue un factor clave para la creación del autorretrato fotográfico?

c. ¿La guía de los elementos creativos le permitió relacionar la fotografía, la memoria y el habitar del territorio para lograr la representación visual?

d. ¿Cree posible que en el resultado final de su creación desarrolló un espacio para reflexionar y proponer una postura crítica hacia el territorio?

e. Evaluar el nivel de complejidad de los procesos creativos a través del autorretrato fotográfico, siendo el nivel 1 el máximo de confusión y el nivel to el máximo de comprensión.

Las respuestas de la evaluación de las primeras cuatro preguntas no indicaron respuestas negativas; en cambio, la quinta pregunta (direccionada a evaluar el nivel de complejidad de los elementos creativos) presentó un comportamiento diferente (figura 10).

\section{Figura 10}

Análisis gráfico de los porcentajes de los niveles de comprensión y confusión de los elementos creativos

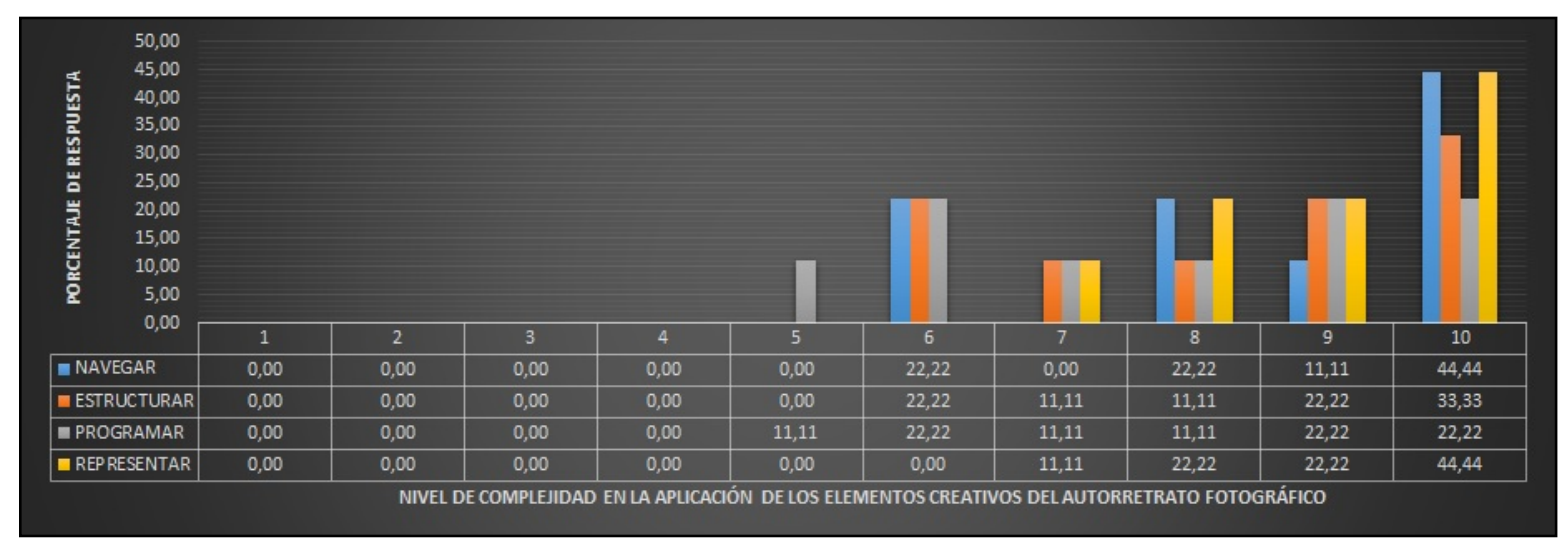


Al comparar los porcentajes en la figura 10 se evidenció que navegar y representar se constituyen como los elementos más comprensibles con un $44.44 \%$ de respuestas en el nivel 10; un nivel de comprensibilidad intermedio del $33.33 \%$ para estructurar; y el más bajo del $22.22 \%$ para el elemento programar, siendo este el que representó el mayor nivel de complejidad. Estos porcentajes permitieron inferir que la operación de tecnologías para el desarrollo creativo presentó un cierto grado de dificultad; sin embargo, los y las jóvenes - a través de las actividades pedagógicas - desarrollaron habilidades técnicas y potenciaron sus destrezas para programar el mensaje visual. En este sentido, los elementos creativos abrieron nuevos caminos para comprender la condición del PC, la apropiación del territorio y sus modos de habitar; de tal manera, los autorretratos fotográficos integraron memorias y habilidades técnicas para la producción de mensajes cargados con sentido social.

\section{Discusión}

Es importante aclarar que el propósito de este texto busca evidenciar las relaciones de dos problemas de investigación de tesis doctoral que permitieron reconocer el autorretrato fotográfico como la base del PC de los y las jóvenes para crear posturas críticas sobre el territorio. Fundamentado en lo anterior, se valora la creación fotográfica, el trabajo de campo empírico y el PC sobre el territorio como un artefacto cultural que permitió desarrollar habilidades para el desarrollo de representaciones visuales y la manipulación de tecnologías que lo hicieran posible. El autorretrato fotográfico se convirtió en una interfaz comunicativa que les permitió expresar memorias, reencuentros con el territorio, integrar la comunidad y relatar visualmente diferentes modos de navegar y habitar el Kilómetro 41.

Los temas abordados permitieron comprender que la creación fotográfica, el diseño y la tecnología son componentes de una línea de pensamiento donde la literatura es escasa, mientras que es más amplia en el sentido general (de la fotografía) como estatuto científico, comercial, artístico y documental. El diseño fotográfico es un problema de la comunicación visual poco explorado; sin embargo, las diferentes triangulaciones teóricas relacionadas en el artículo se convirtieron en materia suficiente para delimitar un camino para el análisis y la comprobación de un esquema de elementos creativos que permitieron crear nuevas relaciones teóricas. 
La creación fotográfica basada en la semiótica, la retórica, el artefacto y la comunicación visual se convierte en una unidad conceptual, en la cual fue posible plantear un primer acercamiento para postular los principios creativos necesarios para que el diseñador fotográfico construya sentido a través de la representación del mensaje visual. Al ser analizados estos supuestos a través de la propuesta de un trabajo de campo piloto, fue posible aplicar instrumentos etnográficos de observación participante y herramientas de análisis para la información visual.

Es de destacar que los resultados del análisis y la evaluación del trabajo piloto determinaron plantear una estructura más coherente sobre los principios creativos basados en el problema de la navegación y la interpretación visual de los participantes al observar el territorio. En este contexto se diseñó un nuevo esquema creativo relacionado a través de sus elementos fundamentales. En tanto que el pilotaje se basó en la aplicación de una guía de principios creativos en diseño fotográfico social dirigido a estudiantes universitarios, el trabajo de campo fase 2 fue dirigido a jóvenes bachilleres del Kilómetro 41, en el cual la autorreferencia fotográfica, el desarrollo del PC y la pedagogía visual se convirtieron en acciones claves para el desarrollo creativo de autorretratos fotográficos.

Sobre los resultados de estos instrumentos metodológicos se destacaron dos discusiones. La primera permitió inferir que los cuatro elementos creativos (estructurar, navegar, programar y representar) son los componentes fundamentales de un modelo de producción basado en la observación; es decir, un sistema de semiosis que permite conectar la documentación fotográfica, la memoria visual y las características que los y las jóvenes interpretan del territorio que habitan. La segunda discusión, producto de los resultados de la primera, posibilitó evidenciar un nuevo problema basado en los procesos cognitivos que producen la creación fotográfica. Estas discusiones permitieron reconocer que la construcción de este modelo, no solo se logra a través de la práctica y la producción creativa desarrollada por el PC y la tecnología, sino que también es construida por medio de una profunda condición interna que lleva al creador fotográfico a desarrollar pensamiento visual.

A través de la anterior conclusión, se reconoce que los procesos cognitivos que llevaron a la mente de los jóvenes y las jóvenes a activar los elementos de producción de autorretratos fotográficos en el territorio se dieron gracias a la estructuración de un modelo cognitivo que dependió de relaciones semióticas, psicológicas y emocionales que, al ser traducidas como una forma de pensamiento visual, suponen un juego creativo desarrollado a través de la conciencia, la inteligencia y el pensamiento. De estas reflexiones se 
infiere que los autorretratos fotográficos son artefactos comunicativos que permitieron a los jóvenes visualizar expresiones, compartir experiencias, interpretar la memoria, así como desarrollar habilidades para navegar y documentar visualmente el territorio. Por tanto, una de las principales contribuciones que aporta esta investigación apunta a disminuir la brecha epistemológica de la comunicación visual dada entre la creación fotográfica, las ciencias sociales, la tecnología y la pedagogía visual. En la condición que los jóvenes y las jóvenes desarrollaron herramientas retóricas para logar la composición del autorretrato fotográfico, se potenció el uso de los elementos creativos para narrar memorias y tránsitos que integraron el PC con el territorio.

Los autorretratos fotográficos basados en el PC permitieron ampliar las percepciones de los lugares y sus modos de habitar. Así, los elementos creativos ampliaron lugares focales de reflexión, como también ampliaron la exploración de procesos pedagógicos que activaron el desarrollo de habilidades y destrezas compositivas basadas en el uso adecuado de tecnologías.

En el sentido de lo anterior, la fotografía como medio de expresión autorreferencial permitió a los jóvenes representar memorias en diferentes lugares, los cuales fueron transformados, ampliados y diversificados como huellas vivenciales para la reconciliación con su territorio; esto fueron posteriormente extendidos a la población a través de la socialización en escenarios académicos y comunitarios.

\section{Agradecimientos}

A los jóvenes y las jóvenes del Kilómetro 41, quienes entregaron toda su condición humana e intelectual para comprender el territorio y expresarlo visualmente.

\section{Referencias}

Acaso, M. (2011). El lenguaje visual. Paidós.

Alberich, T., Arnanz, L., Basagoiti, M., Belmonte, R., Bru, P., Espinar, C., García, N., Habegger, S., Heras, P., Hernández, D., Lorenzana, C., Martín, P., Montañés, M., Villasante, T., \& Tenze, A. (2009). Metodologías participativas. Observatorio Internacional de Ciudadanía y Medio Ambiente Sostenible.

Belting, H. (2007). Antropología de la imagen. Katz. 
Bloomfield, D. (2015). Clarificando términos: ¿qué podemos entender por reconciliación? En Reconciliación: perspectivas y aportes conceptuales para su comprensión (pp. 11-34). Centro de Investigación y Educación Popular.

Brea, J. L. (2002). La era postmedia: acción comunicativa, prácticas (post)artísticas y dispositivos neomediales. Casa.

Buchanan, R. (1985). Declaración por diseño: retórica, argumentación y demostración en la práctica del diseño. Design Issue, 2(1), 4-22.

Buchanan, R. (1990). Problemas perversos en el pensamiento del diseño. Compiègne.

Díaz-Barriga, F., Vázquez-Negrete, V. I., \& Díaz-David, A. (2019). Sentido de la experiencia escolar en estudiantes de secundaria en situación de vulnerabilidad. Revista Latinoamericana de Ciencias Sociales, Niñez y Juventud, 17(1), 237-252. https://doi.org/ $10.11600 / 1692715 \times .17114$

Facione, P. A. (2007). Pensamiento crítico: ¿qué es y por qué es importante? Eduteka. http://eduteka.icesi.edu.co/pdfdir/PensamientoCriticoFacione.pdf

Gamonal, R. (2011). Retórica aplicada a la enseñanza del diseño gráfico. Revista Ícono14, 9 (3), 426-438. https://doi.org/10.7195/ri14.v9i3.128

Goodnow, T. (2016). The selfie moment: The rhetorical implications of digital self portraiture for culture. En A. Benedek, \& Á. Veszelszki (Eds.), In the beginning was the image: The omnipresence of pictures: Time, truth, tradition (pp. 123-130). Peter Lang. https://doi.org/10.3726/b10396

Gutiérrez, J., \& Delgado, J. M. (eds.) (1995). Métodos y técnicas cualitativas de investigación en ciencias sociales. Síntesis.

Hernández, R., Fernández, C., \& Baptista, P. (2014). Metodología de la investigación. McGraw-Hill.

Jiménez, M. (2015). Ser joven en Colombia: subjetividades, nuevas tecnologías y conflicto armado. Entrevista a Germán Muñoz. Revista Latinoamericana de Ciencias Sociales, Niñez y Juventud, 13(1), 437-445.

Lévy, P. (2004). Inteligencia colectiva: por una antropología del ciberespacio. Organización Panamericana de la Salud. http://inteligenciacolectiva.bvsalud.org/public/ documents/pdf/es/inteligenciaColectiva.pdf

López, R., \& Villa, G. A. (2017). El aula de diseño como escenario de exploración entre alfabetidad visual y pensamiento crítico. Revista Kepes, 14(15), 173-194. https:// doi.org/10.17151/kepes.2017.14.15.7

Manovich, L. (2006). El lenguaje en los nuevos medios de comunicación: la imagen en la era digital. Paidós. 
McLuhan, M., \& Powers, B. R. (1995). La aldea global. Gedisa.

Mitchell, W. J. T. (2009). Teoría de la imagen: ensayos sobre la representación verbal y visual. Akal.

Morris, C. (1985). Fundamentos de la teoría de los signos. Paidós.

Pardo, J. (1991). Sobre los espacios pintar, escribir, pensar. Serbal.

Patiño, H. (2014). El pensamiento crítico como tarea central en la educación humanista. Didac, (64), 3-9.

Peirce, C. S. (1987). Obra lógico semiótica. Taurus.

Reygadas, L. (2014). Todos somos etnógrafos: igualdad y poder en la construcción del conocimiento antropológico. En C. Oehmichen (Ed.), La etnografía y el trabajo de campo en las ciencias sociales (pp. 91-118). Universidad Nacional Autónoma de México.

Sontag, S. (2006). Sobre la fotografía. Alfaguara.

Susperregui, J. M. (1987). La fotografía como medio de comunicación de las masas. Kobie.

Torres, D. L., Fonseca, W. P., \& Pineda, B. N. (2017). Las vivencias como estrategia de fortalecimiento del pensamiento crítico en educación rural. Praxis y Saber, 8(17), 201-224. https://doi.org/10.19053/22160159.v8.117.2018.7207

Walsh, C. (2005). Pensamiento crítico y matriz (de)colonial: reflexiones latinoamericanas. Abya Yala. 